\title{
Open challenge for the diagnosis of cow's milk protein allergy
}

\author{
Teste de desencadeamento aberto no diagnóstico de alergia à proteína do leite de vaca \\ Fernanda Ferreira Correa1, Mário César Vieira ${ }^{2}$, Danielle Reis Yamamoto², \\ Patrícia da Graça Leite Speridião ${ }^{3}$, Mauro Batista de Morais ${ }^{4}$
}

\section{Resumo}

Objetivo: Relatar os resultados de testes de desencadeamento aplicados em crianças alimentadas com dieta de exclusão das proteínas do leite de vaca.

Descrição: Estudo transversal que avaliou testes de desencadeamento oral aberto, com leite de vaca, realizados sob supervisão em ambiente hospitalar por 2,5 horas e ambulatoriamente por 30 dias quando não ocorreu reação imediata. Foram incluídos 121 pacientes, com idades entre 4 e 95 meses. $O$ teste de desencadeamento com leite de vaca foi positivo em $28(23,1 \%)$ pacientes. Manifestação clínica de alergia ao leite de vaca diferente da apresentada por ocasião da suspeita diagnóstica ocorreu em 12 (42,9\%) pacientes com desencadeamento positivo. $O$ desencadeamento positivo foi mais frequente $(p=0,042)$ nos pacientes alimentados com fórmulas extensamente hidrolisadas ou de aminoácidos (30,3\%) quando comparados com os alimentados com outras dietas de exclusão $(14,5 \%)$.

Conclusão: $O$ teste de desencadeamento permitiu que fosse suspensa a dieta de exclusão de grande parte dos pacientes.

J Pediatr (Rio J). 2010;86(2):163-166: Alergia a leite/diagnóstico, proteínas do leite, leite de vaca, diagnóstico, tolerância imunológica.

\section{Introdução}

Em lactentes, a alergia alimentar mais frequente é a ocasionada pelas proteínas do leite de vaca ${ }^{1-4}$, que, em geral, provoca manifestações digestivas e cutâneas. O teste de desencadeamento (desafio, provocação ou reexposição oral) é de grande importância na abordagem diagnóstica das crianças com suspeita de alergia ao leite de vaca ou daquelas que vêm recebendo dieta de exclusão para que se caracterize o desenvolvimento de tolerância às proteínas do leite ${ }^{1-5}$. Existem três tipos de teste de desencadeamento: duplo-cego controlado por placebo, simples-cego e aberto. Para os lactentes, grupo etário no qual predominam as reações tardias mediadas por células, a Sociedade Europeia de Gastroenterologia Pediátrica e Nutrição recomenda que seja

\begin{abstract}
Objective: To report the results of open challenge tests performed in children fed with cow's milk-free diet.

Description: Cross-sectional study evaluating cow's milk open challenge performed under supervision in a hospital setting during 2.5 hours and ambulatory follow-up for 30 days when no immediate reaction occurred. One hundred and twenty-one patients were included, with ages between 4 and 95 months. Cow's milk open challenge tests were positive in 28 patients $(23.1 \%)$. A clinical manifestation of cow's milk allergy different from the one presented at diagnosis occurred in 12 (24.9\%) patients with positive challenge. Positive challenge was more frequent $(p=0.042)$ in patients fed with extensively hydrolyzed formulae or amino acid-based formulae (30.3\%) when compared to those fed with other exclusion diets (14.5\%).
\end{abstract}

Conclusion: Open challenge allowed the interruption of exclusion diet in a significant proportion of the patients.

J Pediatr (Rio J). 2010;86(2):163-166: Milk allergy/diagnosis, milk protein, cow's milk, diagnosis, immunologic tolerance.

realizado o teste de desencadeamento aberto ${ }^{6}$. Uma revisão recente considera o desencadeamento aberto apropriado também para os quadros de alergia alimentar com reação mediada pela imunoglobulina e em menores de 3 anos de idade $^{7}$. Deve ser ressaltado que o teste de desencadeamento não deve ser realizado quando as manifestações clínicas pregressas sejam graves e possa existir risco de morte, como, por exemplo, frente ao antecedente de reação anafilática.

O objetivo desta comunicação breve é relatar os resultados de um protocolo de desencadeamento aberto realizado em dois serviços brasileiros de gastroenterologia pediátrica em crianças alimentadas com dieta de exclusão das proteínas do leite de vaca.

1. Nutricionista, Disciplina de Gastroenterologia Pediátrica, Universidade Federal de São Paulo (UNIFESP), São Paulo, SP.

2. Mestre. Centro de Gastroenterologia Pediátrica, Hospital Pequeno Príncipe, Curitiba, PR

3. Doutora, Curso de Nutrição, UNIFESP, Santos, SP.

4. Livre-docente, Disciplina de Gastroenterologia Pediátrica, UNIFESP, São Paulo, SP.

Não foram declarados conflitos de interesse associados à publicação deste artigo.

Como citar este artigo: Correa FF, Vieira MC, Yamamoto DR, Speridião PG, de Morais MB. Open challenge for the diagnosis of cow's milk protein allergy. J Pediatr (Rio J). 2010;86(2):163-166.

Artigo submetido em 27.07.09, aceito em 17.10.09.

doi:10.2223/JPED.1967 


\section{Métodos}

Neste estudo transversal foram incluídos os resultados do primeiro teste de desencadeamento com leite de vaca realizado em 121 pacientes dos ambulatórios de Gastroenterologia Pediátrica da Universidade Federal de São Paulo (UNIFESP), São Paulo (SP), e do Hospital Pequeno Príncipe, Curitiba (PR). A coleta de dados foi realizada no período de junho de 2006 a outubro de 2008. Foram incluídos no estudo $121(89,0 \%)$ dos 136 testes de desencadeamento realizados no período, para os quais foram coletadas todas as informações necessárias. Foram coletados os dados demográficos e as manifestações clínicas que motivaram a hipótese diagnóstica de alergia ao leite de vaca.

O teste de desencadeamento, nos dois ambulatórios, seguiu o mesmo protocolo1-5. Foram realizados pela manhã, com os pacientes em jejum, sob supervisão de pediatra gastroenterologista e nutricionista. Antes do início do procedimento foi realizado exame físico com especial atenção na avaliação da pele, ausculta pulmonar e avaliação do abdome. Crianças que não se apresentavam aptas, ou seja, que apresentavam algum sinal ou sintomas que pudessem dificultar a interpretação do teste, permaneceram com a dieta de exclusão até sua plena recuperação para novo agendamento do teste de desencadeamento. O início do teste foi realizado no ambulatório no qual se dispunha de material para atendimento de emergência. Em nenhum paciente foi instalado acesso venoso antes da administração do leite de vaca. O teste de desencadeamento se estendeu por 30 dias, sendo que as primeiras 2,5 horas foram realizadas nos serviços de saúde.

Inicialmente, o leite de vaca foi colocado em contato na região perioral com auxílio de uma gaze. Após $30 \mathrm{mi}-$ nutos foram administrados, por via oral, $10 \mathrm{~mL}$ de leite de vaca integral ou fórmula infantil, com um esquema progressivo de aumento de volume, dobrando-se a dose a cada 20-30 minutos por 2,5 horas. Aos 150 minutos foi finalizada a primeira etapa do teste de desencadeamento no serviço de saúde. O teste era interrompido e considerado positivo quando ocorria uma ou mais das seguintes reações compatíveis com alergia à proteína do leite de vaca: vômitos, diarreia, presença de sangue nas fezes, lesão cutânea eritematosa ou edematosa compatível com urticária, rinoconjuntivite e sibilância. As crianças que não apresentavam reações sugestivas de alergia às proteínas do leite de vaca eram dispensadas para continuação do teste ambulatoriamente. Esta segunda etapa se estendeu por 30 dias, recomendando-se que nesse período as crianças consumissem leite de vaca e derivados todos os dias. No final deste período, confirmou-se que os pacientes consumiram leite de vaca e derivados e que não ocorreram manifestações clínicas indicativas de alergia alimentar. Quando os pais não retornavam ao final dos 30 dias, foi realizada entrevista por telefone. Ao final desse período, quando o paciente permanecia assintomático, o teste de desencadeamento foi considerado negativo.

O projeto foi aprovado pelo Comitê de Ética institucional, sendo obtido consentimento esclarecido por escrito dos responsáveis.

\section{Resultados}

Do total de 121 pacientes em dieta de exclusão do leite de vaca e derivados, $69(57,0 \%)$ eram do sexo masculino. No momento do desencadeamento, a idade variou de 4 a 95 meses, sendo a média igual a 16,9 $9 \pm 11,9$ meses. As manifestações clínicas ao início da dieta de exclusão incluíram diarreia $(28,6 \%)$, vômitos ou regurgitação $(27,9 \%)$, sangue nas fezes $(23,5 \%)$, irritabilidade $(16,9 \%)$, cólica ou dor abdominal $(13,2 \%)$, dermatite atópica $(11,0 \%)$, manifestações urticariformes $(9,5 \%)$, constipação $(8,1 \%)$, sibilância $(6,6 \%)$, diarreia com sangue $(5,8 \%)$, distensão abdominal (4,4\%), edema alérgico na face ou orelha $(2,9 \%)$, hematêmese $(2,2 \%)$, otite $(2,2 \%)$ e rinite $(0,7 \%)$. Dos 121 pacientes, $20(14,5 \%)$ haviam realizado teste de desencadeamento considerado positivo antes de serem referenciados para os ambulatórios especializados.

A duração da dieta de exclusão foi menor que 12 semanas em 31 (25,6\%) pacientes; entre 12 e 23 semanas em 28 $(23,1 \%)$; entre 24 e 47 semanas em $42(34,7 \%)$; e maior que 48 semanas em 20 (16,5\%).

O teste de desencadeamento foi positivo em 28 (23,1\%) pacientes, sendo que em 14 a manifestação apareceu nas primeiras 4 horas, em sete, em até 24 horas e em três, em mais de 24 horas. A Tabela 1 apresenta as manifestações clínicas ao diagnóstico e durante o teste de desencadeamento. Em nenhum paciente ocorreu manifestação grave do tipo choque anafilático. Manifestação clínica de alergia ao leite de vaca diferente da apresentada por ocasião da suspeita diagnóstica ocorreu em 12 (42,9\%) dos 28 pacientes com teste positivo (Tabela 1). A Tabela 2 apresenta a associação entre a positividade dos testes de desencadeamento com determinadas variáveis. Observou-se maior frequência de testes positivos nas crianças que vinham sendo alimentadas com hidrolisados de proteínas ou fórmula de aminoácidos em relação às alimentadas com soja ou sem substitutos do leite de vaca.

\section{Discussão}

A abordagem da criança com alergia à proteína do leite de vaca inclui a recuperação clínica na vigência da dieta de exclusão e a confirmação diagnóstica por meio do teste de desencadeamento após cerca de 6 a 8 semanas de dieta de exclusão. Quando comprovado o diagnóstico, recomenda-se a repetição de testes de desencadeamento a cada 6 a 12 meses até o desenvolvimento de tolerância imunológica ${ }^{1-5}$

Um dos resultados importantes deste estudo foi que o teste de desencadeamento foi negativo em 93 (76,8\%) dos 121 pacientes estudados. Nesses casos foi possível suspender a dieta de exclusão do leite de vaca e derivados. Essa conduta representa importante redução dos custos com a dieta substitutiva, em especial com uso de fórmulas com proteínas extensamente hidrolisadas ou de aminoácidos e, ainda, a redução dos riscos nutricionais aos quais está sujeito o paciente em dieta de exclusão8,9. Outro ponto que deve ser ressaltado é a necessidade de os pacientes com teste de desencadeamento negativo serem acompanhados de forma cuidadosa, considerando-se que podem ocorrer reações subclínicas da alergia ao leite de vaca10,11. 
Em 42,9\% (12/28) dos testes positivos ocorreram manifestações clínicas diferentes daquelas que motivaram a suspeita diagnóstica de alergia ao leite de vaca. Na década de 60, no clássico artigo de Goldman et al. ${ }^{12}$, exigia-se o reaparecimento das mesmas manifestações clínicas em três testes de desencadeamento para que o diagnóstico de alergia alimentar fosse confirmado. Atualmente, aceita-se apenas um teste de desencadeamento positivo como critério diagnóstico ${ }^{1-5}$. No entanto, mesmo que ao longo do tempo as manifestações clínicas da alergia possam apresentar modificações, deve-se considerar a possibilidade de parte desses resultados positivos ser atribuída a outras intercorrências clínicas. Além disso, o médico deve estar atento a possíveis informações incorretas fornecidas pela família. A alergia alimentar pode ser simulada na síndrome de Munchausen por procuração ${ }^{13,14}$. Frente a um resultado positivo não característico ou inesperado, é aconselhável a repetição do teste de desencadeamento em curto intervalo de tempo. Por outro lado, quando um teste é negativo, deve ser considerada, também, a possibilidade de que poucas semanas após o início da dieta de exclusão tenha ocorrido tolerância à proteína alergênica.

Um aspecto que deve ser ressaltado é o período pelo qual os pacientes permaneceram em dieta de exclusão: 20 pacientes estavam em dieta de exclusão por 48 semanas (aproximadamente 11 meses), e 42 estavam entre 24 e 48 semanas. Nesse contexto, deve ser considerado que grande parcela dos pacientes estudados estava realizando teste de desencadeamento para caracterização do desenvolvimento

Tabela 1 - Sexo, idade e manifestações clínicas no momento da suspeita diagnóstica e durante o teste de desencadeamento.

\begin{tabular}{|c|c|c|c|c|c|}
\hline Sexo & $\begin{array}{c}\text { Idade } \\
\text { (meses) }\end{array}$ & $\begin{array}{l}\text { Manifestação } \\
\text { clínica inicial }\end{array}$ & $\begin{array}{c}\text { Manifestação } \\
\text { no desencadeamento }\end{array}$ & $\begin{array}{l}\text { Mesmo tipo de } \\
\text { manifestação } \\
\text { do início }\end{array}$ & $\begin{array}{l}\text { Tempo decorrido } \\
\text { para aparecimento } \\
\text { da reação (horas) }\end{array}$ \\
\hline $\mathrm{F}$ & 16 & Vômitos & Vômitos & Sim & $<4$ \\
\hline M & 34 & $\begin{array}{l}\text { Diarreia, distensão abdominal, } \\
\text { edema alérgico na face e orelha }\end{array}$ & Urticária & Sim & $<4$ \\
\hline M & 11 & Urticária, vômitos & $\begin{array}{l}\text { Edema de lábio inferior } \\
\text { e hiperemia perioral }\end{array}$ & Sim & $<4$ \\
\hline M & 31 & Constipação, sangue nas fezes & Sangue nas fezes & Sim & $<4$ \\
\hline M & 13 & Diarreia e vômitos & Náusea & Não & $<4$ \\
\hline M & 28 & Diarreia e vômitos & $\begin{array}{l}\text { Diarreia, vômitos e } \\
\text { dor abdominal }\end{array}$ & Sim & 9 \\
\hline M & 31 & Constipação, sangue nas fezes & Sangue nas fezes & Sim & $<4$ \\
\hline M & 14 & Sibilância, diarreia & Sibilância & Sim & 48 \\
\hline M & 7 & Falta de ar e urticária & Urticária & Sim & $<4$ \\
\hline M & 20 & Diarreia & Urticária & Não & $<4$ \\
\hline M & 15 & Sibilância, deficit ponderoestatural, vômitos & Sibilância & Sim & $<4$ \\
\hline M & 14 & Urticária & Urticária & Sim & $<4$ \\
\hline M & 5 & Diarreia com sangue, irritabilidade & Urticária & Não & \\
\hline M & 4 & Constipação, deficit ponderoestatural & Vômitos, tosse, flatulência & Não & $<4$ \\
\hline M & 5 & Dor abdominal, irritabilidade & Cólica intensa & Sim & $<4$ \\
\hline $\mathrm{F}$ & 9 & Diarreia com sangue & Vômitos & Não & $<4$ \\
\hline $\mathrm{F}$ & 24 & Diarreia & Vômitos & Não & $<4$ \\
\hline $\mathrm{F}$ & 12 & Deficit ponderoestatural, urticária & $\begin{array}{c}\text { Sibilância, edema palpebral, } \\
\text { prurido ocular }\end{array}$ & Sim & \\
\hline M & 15 & Dor abdominal, sangue nas fezes, vômitos & Diarreia & Não & 48 \\
\hline $\mathrm{F}$ & 7 & Deficit ponderoestatural, diarreia & Diarreia e vômitos & Sim & 48 \\
\hline M & 12 & Diarreia, dor abdominal & Diarreia & Sim & 24 \\
\hline $\mathrm{F}$ & 5 & Diarreia com sangue, dor abdominal & Diarreia com sangue & Sim & 24 \\
\hline M & 12 & Vômitos & Diarreia e vômitos & Sim & 24 \\
\hline M & 15 & Sibilância, sangue nas fezes & Diarreia & Não & 24 \\
\hline $\mathrm{F}$ & 12 & Distensão abdominal, sangue nas fezes & Diarreia e vômitos & Não & 48 \\
\hline M & 19 & Anorexia, baixo ganho de peso, irritabilidade & Urticária & Não & 24 \\
\hline $\mathrm{F}$ & 12 & Anorexia, baixo ganho de peso & Irritabilidade, cólicas & Não & 24 \\
\hline $\mathrm{F}$ & 12 & Diarreia com sangue e vômitos & $\begin{array}{l}\text { Sibilância, urticária, } \\
\text { deficit de ganho de peso }\end{array}$ & Não & \\
\hline
\end{tabular}


Tabela 2 - Avaliação de associação entre teste de desencadeamento positivo e determinadas variáveis

\begin{tabular}{|c|c|c|c|}
\hline & \multicolumn{2}{|c|}{ Teste de desencadeamento com leite de vaca } & \multirow[b]{2}{*}{ p* } \\
\hline & Positivo, n (\%) & Negativo & \\
\hline \multicolumn{4}{|l|}{ Gênero } \\
\hline Masculino & $19(27,5)$ & 50 & \\
\hline Feminino & $9(17,3)$ & 43 & 0,188 \\
\hline \multicolumn{4}{|l|}{ Idade } \\
\hline$\geq 12$ meses & $20(21,5)$ & 73 & \\
\hline$<12$ meses & $8(28,5)$ & 20 & 0,793 \\
\hline \multicolumn{4}{|l|}{ Manifestação clínica inicial ${ }^{\dagger}$} \\
\hline Digestiva & $24(21,8)$ & 86 & \\
\hline Cutânea & $6(24,0)$ & 19 & \\
\hline Respiratória & $2(28,6)$ & 5 & 0,901 \\
\hline \multicolumn{4}{|c|}{ Duração da dieta de exclusão das proteínas do leite de vaca } \\
\hline$\leq 12$ semanas & $4(12,9)$ & 27 & \\
\hline 13-24 semanas & $9(32,1)$ & 19 & \\
\hline $25-47$ semanas & $8(19,0)$ & 34 & \\
\hline$\geq 48$ semanas & $7(35,0)$ & 13 & 0,166 \\
\hline \multicolumn{4}{|c|}{ Tipo de substituto do leite de vaca } \\
\hline Fórmula ou extrato de soja & $5(11,9)$ & 37 & \\
\hline Hidrolisado de proteínas & $18(34,6)$ & 34 & \\
\hline Fórmula de aminoácidos & $2(14,3)$ & 12 & \\
\hline Sem fórmula & $3(23,1)$ & 10 & 0,058 \\
\hline
\end{tabular}

* Teste do qui-quadrado com correção de Mantel-Haenszel.

† Cada paciente poderia apresentar mais de um tipo de manifestação clínica na admissão.

Teste do qui-quadrado com correção de Mantel-Haenszel - hidrolisado de proteínas + aminoácidos $(30,3 \%)$ versus soja + sem fórmula (14,5\%) - p = 0,042.

de tolerância e não para confirmar o diagnóstico de alergia ao leite de vaca propriamente dito. Muitos pacientes foram encaminhados para o serviço especializado a fim de realizar o teste de desencadeamento. Outro aspecto que explica o longo período de dieta de exclusão é o fato de parcela dos pacientes apresentar na anamnese informações de reações adversas recentes quando ingeriram propositalmente ou não alimentos com leite de vaca ou derivados. Nesse contexto, no acompanhamento do paciente em dieta de exclusão é importante pesquisar se as proteínas do leite de vaca não estão sendo efetivamente utilizadas.

Em conclusão, não se observou nenhuma reação de gravidade por ocasião dos testes de desencadeamento, mesmo porque $o$ antecedente de reação alérgica grave foi considerado uma contraindicação. Nos pacientes com teste positivo e manifestação diferente do quadro clínico original, deve ser considerada a possibilidade de resultado falso positivo, sendo necessária reavaliação do diagnóstico. Por sua vez, grande parte dos pacientes foi liberada da dieta de exclusão, o que confirma o grande valor do teste de desencadeamento no acompanhamento desses casos.

\section{Referências}

1. Sampson HA. Update on food allergy. J Allergy Clin Immunol. 2004;113:805-19; quiz 820.

2. American College of Allergy, Asthma, \& Immunology. Food allergy: a practice parameter. Ann Allergy Asthma Immunol. 2006;96 Suppl 2:S1-68.

3. Toporovski MS, Vieira MC, Spolidoro JV, Morais MB, Fagundes-Neto U. Alergia ao leite de vaca. In: Lopez FA, Campos Jr D. Tratado de Pediatria - Sociedade Brasileira de Pediatria. Barueri: Manole; 2007. p. 863-71.
4. Vandenplas $Y$, Koletzko S, Isolauri E, Hill D, Orange AP, Brueton $M$, et al. Guidelines for the diagnosis and management of cow's milk protein allergy in infants. Arch Dis Child. 2007;92:902-8.

5. Bock SA. Diagnostic evaluation. Pediatrics. 2003;111:1638-44.

6. Diagnostic criteria for food allergy with predominantly intestinal symptoms. The European Society for Paediatric Gastroenterology and Nutrition Working Group for the Diagnostic Criteria for Food Allergy. J Pediatr Gastroenterol Nutr. 1992;14:108-12.

7. Bahna SL. Food challenge procedure: optimal choices for clinical practice. Allergy Asthma Proc. 2007;28:640-6.

8. Medeiros LC, Speridião PG, Sdepanian VL, Fagundes-Neto U, Morais MB. Ingestão de nutrientes e estado nutricional de crianças em dieta isenta de leite de vaca e derivados. J Pediatr (Rio J). 2004;80:363-70.

9. Paganus A, Juntunen-Backman K, Savilahti E. Follow-up of nutritional status and dietary survey in children with cow's milk allergy. Acta Paediatr. 1992;81:518-21.

10. Iynkaran $N$, Robinson $M J$, Prathap $K$, Sumithran $E$, Yadav $M$. Cow's milk protein-sensitive enteropathy. Combined clinical and histological criteria for diagnosis. Arch Dis Child. 1978;53:20-6.

11. Latcham F, Merino F, Lang A, Garvey J, Thomson MA, WalkerSmith JA, et al. A consistent pattern of minor immunodeficiency and subtle enteropathy in children with multiple food allergy. J Pediatr. 2003;143:39-47.

12. Goldman AS, Anderson DW Jr, Sellers WA, Saperstein S, Kniker WT, Halpern SR. Milk Allergy. I. Oral challenge with milk and isolated milk proteins in allergic children. Pediatrics. 1963;32:425-43.

13. Roesler TA, Barry PC, Bock SA. Factitious food allergy and failure to thrive. Arch Pediatr Adolesc Med. 1994;48:1150-5.

14. Morais MB, Marchette AC, Speridião PG, Lopes LH, Robles RM, Benedito MD, et al. Síndrome de Munchausen por terceiro simulada como alergia alimentar múltipla: relato de caso. Rev Paul Pediatria. $2006 ; 24: 373-8$

Correspondência:

Mauro Batista de Morais

Rua Pedro de Toledo, 441

CEP 04039-031 - São Paulo, SP

E-mail: mbmorais@osite.com.br 